\section{Reintroductions, introductions, and the importance of post-release monitoring: lessons from Zanzibar}

Between 1991 and 1996 Struhsaker \& Siex (1998) made a valiant and worthwhile series of surveys to assess the outcome of earlier attempts to establish viable populations of the Zanzibar red colobus monkey Procolobos kirkii, one of Africa's most endangered primates. Between 1977 and 1981 red colobus were released at three sites in Zanzibar, two of which, Masingini and Kichwele, were believed to have probably held red colobus before the 1800 s, whereas red colobus never naturally occurred at the third site, on the island of Pemba (Struhsaker \& Siex, 1998). The results of the surveys indicated that one of these releases was successful, with red colobus still present and apparently breeding only at Masingini.

In reading this paper I was struck by how it highlighted the importance of the three 'P's of wildlife restoration projects: Preparation, Post-release monitoring and Publication. The paper also revealed a need for improved standardization of terminology.

The expansion of the use of reintroductions as a means to restore threatened species, and the growing need to ensure that any such projects have the greatest possible chance of success, prompted the IUCN/SSC's Reintroduction Specialist Group to produce a series of guidelines for reintroductions (IUCN, 1998). These guidelines set out the stages and requirements for any serious reintroduction attempt. The guidelines also define a number of terms in order to standardize their usage and avoid confusion in the published literature.

Struhsaker \& Siex (1998) considered the release of red colobus into their former range to constitute a translocation, that is 'the capture of free-ranging wild animals in their native habitat and their release into natural or near-natural habitat within their geographical range', distinguishing this from a reintroduction, that is the transfer of captive animals (usually captive-bred) into the wild' (Struhsaker \& Siex, 1998: 278). These definitions are at odds with the ones used in the IUCN Guidelines, where a translocation is 'a deliberate and mediated movement of wild individuals to an existing population of conspecifics', and a reintroduction is 'an attempt to establish a species in an area which was once part its historical range, but from which it has been extirpated or become extinct (IUCN, 1998).

The principal difference with the IUCN definition of reintroduction is that the animal to be released can come from any source, the key point being their release into habitat in which the species is no longer found. The release of red colobus into Masingini and Kichwele would, if historical information is accurate, therefore constitute reintroduction attempts.

The use of the term translocation is less clear. The IUCN Guidelines aim to distinguish this from reintroductions and introductions by requiring that the release be at a site containing conspecifics. Translocation, however, is used in a wider sense in wildlife management to refer generally to any transportation of animals from one site to another, most often a wild-to-wild movement. Translocation perhaps becomes clearer when it is used with regard to movement at the level of the individual (Stanley Price, 1989), whereby wild-caught animals are removed for release into the wild at another site. In this way it is possible to translocate animals as part of a population reintroduction programme. A number of red colobus monkeys could be described as having been translocated to Masingini and Kichwele in order to reintroduce populations of red colobus at these sites.

The term introduction is not defined by Struhsaker \& Siex (1998), but may be inferred to mean the release of animals into habitat outside their historical range. This accords well with the IUCN definition of 'conservation/ benign introduction: an attempt to establish a species, for the purpose of conservation, outside its recorded distribution but within an appropriate habitat and ecogeographical area' (IUCN, 1998). The release of red colobus on to Pemba was correctly described as an introduction.

Perhaps as a result of the definitions they have chosen, Struhsaker \& Siex go on to refer to translocation and introduction as 'two of the last and relatively desperate options: surpassed only by reintroduction ...' (1998: 278). If anything, the introduction of animals into areas outside their normal range may be considered most desperate, implying as it does that there is no remaining area left within the species's historic range. However, it is misleading to consider these actions as desperate, because desperation may lead to hastily contrived and ultimately ineffective programmes. As the process for management and restoration of rare or threatened species becomes more firmly grounded in good science and rigorous protocols, we should rather consider reintroduction, translocation, introduction and other deliberate releases of wildlife as another set of available tools in our expanding conservation kit-bag.

A final point, and one which is well made in the Struhsaker and Siex paper, concerns the difficulty in learning anything useful from release projects that are poorly planned, have little or no follow-up monitoring, and which have not been clearly documented, either as 
publications or internal reports. It is difficult to conclude anything about the apparent failures of the releases at Kichwele and Pemba, because these took place at least 12 years before the surveys, involved the release of unmarked animals and were poorly documented, particularly in the case of Pemba where no written record of the release was available. Although much attention has been focused on the pre-release and release phases of reintroductions, this probably reflects the difficulty and expense of putting adequate post-release monitoring programmes in place. But it is the postrelease monitoring of the survival, dispersal and behaviour of released individuals that will provide the information that is essential for assessment of success or failure. If a release fails to establish a population it is just as important to know why animals have died, migrated or failed to breed. As Struhsaker and Siex can well attest, it is virtually impossible to answer these questions more than a decade after the fact.

\section{Philip J. Seddon}

National Wildlife Research Centre

National Commission for Wildife Conservation

and Development

PO Box 1086 Taif, Saudi Arabia

E-mail: nwrc@compuserve.com

\section{References}

IUCN (1998) Guidelines for Reintroductions. IUCN/SSC Reintroduction Specialist Group. IUCN, Gland, Switzerland and Cambridge, UK.

Stanley Price, M.R. (1989) Animal Reintroductions: The Arabian Oryx in Oman. Cambridge University Press, Cambridge

Struhsaker, T.T. \& Siex, K.S. (1998) Translocation and introduction of the Zanzibar red colobus monkey: success and failure with an endangered island endemic. Oryx, 32, $277-284$.

\section{The rule of law and African game, and social change and conservation misrepresentation- a reply to Spinage}

I write to comment on two papers by Clive Spinage (1996, 1998). Spinage's thesis in the first paper is straightforward-'game' laws were established with good intent, they are necessary, and those who advocate dispensing with them are irresponsible. However, I believe that he is wide of the target in his assumptions about the policies being advocated by the group he is criticizing (to whom I shall refer as the 'radicals' in the remainder of this letter).

I don't think any of the radicals would argue against his postulation that 'game' laws were promulgated at all times with good intent. Throughout history laws have been made with good intent. It is only in retrospect that it is possible to review the shortcomings of classic colonial wildlife legislation, which relies on centralized state control to achieve its ends. Where Spinage is critical of the 'socialist-inspired motives' of the radicals, nothing could be more socialist-Marxist than the monolithic bureaucratic system he espouses as the desirable approach (Martin, 1996). Whatever the motivation, the de facto situation is as Child (1995) stated it: colonial legislation has had the effect of alienating wildlife from local peoples, has failed to reverse species' population declines because of its unenforceability, and has failed to provide any incentives for conservation.

Spinage uses a somewhat circular argument when he states that the fact that African game laws remained unaltered in many African countries after independence is indicative of the fact that 'suitable, acceptable alternatives' cannot be found. A much simpler explanation is to be found in the inertia of state bureaucracies and their mindless preservation of systems that empower them. It is generally in those countries where no attempts have been made to alter colonial law that the greatest wildlife declines have occurred.

Spinage is mischievous in giving the impression that the radicals are advocating the total abrogation of game laws. The statement in his abstract that the 'abrogation of such laws will not lead to a lessening of the increasing destruction of African wildlife' is perhaps the window into the thought processes that motivate the entire paper. There is a fatalistic assumption that everywhere wildlife is decreasing-which is not true. And given this assumption, there follows the rather negative approach that even if the law is failing it is better than no law. He does not consider that there may be an alternative suite of enabling laws that provide the economic and proprietorial incentives for landholders to retain and manage wildlife on their land. Landholders in this situation require the full backup of the law as much as the State does because they too will have to deal with illegal hunting of wildlife. However, if they are able to offset the overhead costs of protection against the returns from wildlife, this may lead to viable land-use systems.

Spinage is wrong when he assumes that the radicals are arguing for a return to traditional African customary law: rather they seek law that is appropriate for the reality of current African society. Having made this incorrect assumption he goes on to back it up by citing examples of people in remote areas who have not been affected by colonial law and whose traditional systems have nevertheless failed to achieve conservation of wildlife. These examples do not prove the point. There is a big difference between an absence 
of law and pro-active law that promotes wildlife as a land use and facilitates legal marketing of its products. Good law must be workable and law that is unenforceable is worse than no law. The required operating budgets for anti-poaching in state-protected areas have proved to be beyond the capacity of most African governments-let alone what would be required to enforce a similar system for the vast areas of land surrounding them. If solutions are to be found to conserve wildlife outside state-protected areas, it will require transferring these enforcement costs to the landholders: in other words, decentralizing both the power and the so-called responsibilities of the State to the persons on whose land the wildlife occurs.

There are good examples in southern Africa of increases in wildlife populations and increasing amounts of land being placed under wildlife management wherever the law enables this form of land use. In Namibia, South Africa and Zimbabwe, where the law empowers landholders on commercial farms and on communal lands to manage their wildlife with a minimum of government interference, populations of most of the large mammals are increasing (Martin, 1993).

Spinage is incorrect when he states that in certain areas of Zimbabwe people have been 'granted the right to ownership of game on their own land, but there remains legal control of rare and endangered species ...'. Wildlife has the legal status of res nullius in Zimbabwe (as described by Spinage himself in the opening paragraph of his paper) and Zimbabwe law does not grant ownership. Rather it confers on the landholder the legal function of Appropriate Authority for wildlife, which is the same role as the State enjoys in state-protected areas. The State exercises some controls over Specially Protected Species (there are no such categories as rare and endangered in Zimbabwe law) and, ironically, these are generally the species whose populations in Zimbabwe are not increasing (e.g. roan antelope) simply because the legislation makes it difficult to help them increase. By prohibiting trading, hunting and sale of live animals, the law removes the active conservation measures that have led to an increase in all other species.

Spinage refers to '... excessive profit-motivated destruction that influenced colonial game law policy in not permitting private ownership and discouraging econonomic incentive'. The reader is being told that only these two simple alternatives exist: state control or overexploitation. Yet the examples given refer to a common access situation, not an institutional system that vests the powers of exclusion with the landholders.

Spinage states that poaching in Britain has never been worse nor more widespread than it is today and uses this to support his argument that granting the right to ownership of game on one's own land does not remove the problem. None of the radicals would dispute this: all successful wildlife populations attract illegal hunters. All that is in dispute is whether the landholder or the State is best able to handle the problem (and its cost).

There are risks in allowing landholders the right to manage their own wildlife and some landholders may eradicate their wildlife. But it has to be recognized that the alternative to state control is worse because it leads to almost universal failure.

In his second paper, Spinage's themes become more complex. Indeed, it is difficult to select a single main argument. Spinage would seem to be simultaneously trying to make the points listed below regarding stateprotected wildlife areas.

1 The traditional approach of total protection in stateprotected wildlife areas always was and still is justified. 2 Despite any perceived historical injustices to neighbouring communities, there is no sound basis for deviating from this policy.

3 The fact that the policy may not have worked is not because there is anything wrong with it but because of human population increase around protected areas and the availability of modern weapons.

4 There are no good reasons for involving local people in the management of such areas-this is the domain of ecologists.

5 The legal exploitation of protected areas by local people should not be countenanced.

He believes that anyone who disagrees with this is a Marxist or neo-populist spouting left-wing political dogma (sic) and misrepresenting the truth. As in his first paper, it does not seem to strike Spinage that the strong central controls he advocates are more characteristic of socialist-Marxist systems than they are of liberal democratic societies.

The objects of Spinage's criticism are largely the contributors to a recent book (Ghimire \& Pimbert, 1997). Yet the heresies they espouse are not new. Parker, Sheldrick and Woodley proposed in 1957 that the Wata (or Waliangulu) people be allowed to hunt elephants lawfully in Tsavo National Park (Parker \& Amin, 1983). The proposal was frustrated through the joint efforts of the wildlife department and the treasury. Parker (in litt.) quotes Col. Neil Sandeman, the Game Warden at Headquarters in 1957, as saying 'Our job is to look after animals, not bloody people!'. Spinage agrees-'... what government would allow a minority of less than 500 persons to maintain customary rights over $40,000 \mathrm{sq} \mathrm{km}$ ?'. However, there is a degree of misrepresentation here. At no stage was it ever intended that the Wata would exercise unbridled rights over Tsavo. Ironically, after this proposal was rejected, they were able to exercise de facto rights over the park very effectively. 
Graham (1973) expressed disquiet at the colonial approach to wildlife conservation and lampooned the fortress mentality. Martin (1978) developed an early community programme in Zimbabwe where neighbouring communities received benefits from state-protected areas. Bell (1987) preached subversion by suggesting that 'poaching' should be legalized in national parks. A large number of other publications dating from the $1980 \mathrm{~s}$ would confirm that the authors Spinage has singled out have no imprimatur on the concepts of community involvement in protected areas.

In his introduction Spinage asks the rhetorical question 'Does there have to be a social purpose [for establishing a park or a reserve]?'. I find this naïve. Nothing done by democratic governments can be without social purpose. In developing its 'ecosystem approach' the Convention on Biological Diversity has enunciated 12 principles (CBD, 1998), the first of which recognizes that management objectives for ecosystems are a matter of societal choice. The given rationale is that 'Ultimately all ecosystems are managed for the benefit of humans-whether that benefit is consumptive or non-consumptive'. The same document recognizes that humans are part and parcel of ecosystems and not separate from them.

The Southern Africa Sustainable Use Specialist Group of IUCN recently reviewed the sustainability of stateprotected areas in southern Africa (SASUSG, 1998). It concluded that the majority of national parks and game reserves were failing to conserve biodiversity, were financially unsustainable and were irrelevant to 95 per cent of the people in the countries where they were located. Where governments were creating national parks they could be seen as 'a crude attempt to capture land and resources for the public good when neither the public nor the good had been defined'. Whether the objectives are to conserve biological diversity or to promote economic growth, there are better ways of doing it than through the mechanism of state conservation areas. The situation now in many parts of southern Africa is that, where full rights of access and control over wildlife have been granted to landholders (of both private and communal land), biodiversity is better conserved in the areas surrounding national parks (Cumming et al., 1997) and they are economically more productive than the state-protected areas (Martin, 1993).

Spinage defends the shooting of illegal hunters by Kenya Wildlife Service and debunks claims by Peluso (1992) that significant numbers of indigenous peoples were killed - rather the targets were Somali shifta carrying arms of war. Parker (in litt.) gives a more sensitive analysis.

Because Somalis poached, the policy of shooting all poachers on sight developed. ... Young

Abakuna [Gumundi] had killed a warthog for the family to eat. Unfortunately, he was apprehended by a group of GSU [General Service Unit] who were supposed to be looking for Somali shifta. He had not resisted arrest. Nevertheless, this wretched group of town-born police, who loathed every second they had to spend in the bush away from dance halls, bars and urban slummery, killed young Abakuna in cold blood. He was executed and left in the bush, the event recorded in brave words: the patrol had encountered a gang of shifta and in the ensuing firefight one of the poachers had been killed.

I am not sure how many people have to be killed before discontent with the practice sets in. Nkudu \& Martin (1991) questioned the moral basis for killing poachers in Zimbabwe.

Spinage uses the example of Moremi Game Reserve in Botswana as a 'failed project' involving local communities in the management of protected areas. However, there is some misrepresentation in his analysis of the case study. First, under no stretch of the imagination could the project have qualified as one of the modern genre of community conservation projects that strive to link full empowerment of communities with full economic returns from the resource. The project was run by a local NGO (The Fauna Conservation Society) with local people represented on the management committee. The Government would not allow collection of fees by the society and, had the project made any profits in its early stages, there was no provision for such profit to be returned to the local community. The Department of Wildlife and National Parks did not support the project and, by dragging its heels in gazetting the boundaries and placing bureaucratic obstacles in the way of the implementers, effectively derailed it (P. A. Smith, Treasurer, Fauna Conservation Society 1965-68, pers. comm.). None of the correct incentives (Murphree, 1997) was in place to give the project a hope of success and Spinage's generic statement that the idea of local communities managing protected areas has been shown not to work is somewhat sweeping.

It is disappointing that someone of Spinage's stature accepts the facile explanation of 'Japanese-backed exploitation of elephants for their ivory' as the explanation for the decline of elephants from 1.3 million in 1970 to less than half that figure today. It is misrepresentation to place such weight on a continental estimate for the elephant population in 1970 when less than 20 per cent of the elephant range had been surveyed. A much simpler explanation for the decline lies in the loss of elephant range-a phenomenon that sits comfortably with Spinage's own diagnosis that human population increase in Africa is the root cause of all ills. However, this is a complex issue and the work of the 
African Elephant Specialist Group should be the reference point.

A detailed examination of this paper reveals some 15 instances where Spinage has levelled claims of misrepresentation against various authors. The Oxford Dictionary of Current English defines misrepresentation as to 'give of a false account of', which has to be seen as a fairly strong accusation. I have examined all of the specific points where misrepresentation is claimed and can find nothing stronger than a difference of opinion between Spinage and his adversaries. Indeed, in several instances it could be claimed that Spinage's postulations are misrepresentations. For example, in the section titled No room for the noble savage', Ghimire \& Pimbert (1997) (who incidentally are not the first to refer to the King's Game syndrome: Graham's [1973] The Gardeners of Eden is the benchmark) are accused of misrepresenting the character of colonial powers by suggesting that they had little respect for traditional rights and use of local peoples. The limited examples presented by Spinage do not prove Ghimire and Pimbert to be guilty of giving a false account of the situation. Spinage himself concedes (p. 274) that 'There is no doubt much truth in some of the arguments of social injustice, and many injustices may have been perpetrated wilfully or ignorantly'. Example after example can be produced that would show that most colonial conservationists were not very conscious of local peoples' rights (Graham, 1973; I. Parker, in litt.). All that held the conservationists in check in colonial times was the counterbalancing influence of the more powerful local government agencies, e.g. District Administrators whose job was to safeguard interests of local peoples. Spinage himself misrepresents colonialists as a single unified community with good intent - the reality is that within the divisions of colonial agencies there were conflicting agendas. Members of the other Government Departments generally viewed staff of wildlife agencies as misguided missionaries.

Mclvor is accused of misrepresenting reality when he suggests that there was 'management' of wildlife by the Shona and Ndebele of Zimbabwe in the 1890s. Strangely, Spinage goes on to support the notion of such management by stating that customary law at the time could result in more severe penalties for infraction than colonial or post-independence law.

Botkin is not wrong when he contrasts the state of the vegetation inside and outside Tsavo National Park. Any layman looking out of the window of a commercial aircraft from an altitude of $7000 \mathrm{~m}$ can see the boundaries of the park and the difference between the vegetation inside and outside without being an experienced ecologist. It is rather like looking at a football field in a London suburb. Spinage may be obscuring the facts with complicated references to higher rainfall on the Chyulu Hills and less favoured habitats of elephant: this explanation does not account for the abrupt discontinuity in vegetation that occurs exactly along all the park boundaries for a distance amounting to several hundred kilometres.

In his section on 'Misrepresenting fact' (are we entitled to believe from this subtitle that all the previous misrepresentations are not on matters of fact?), Spinage comes across weakly. Both he and McIvor (whom he is attacking) have misinterpreted certain aspects of the Zimbabwe wildlife legislation (see my earlier criticisms on the legislative paper).

In his section 'The myth of the Elysian field', Spinage concedes that parks may be in jeopardy when they are islands in a sea of humans, but does not believe that 'abandoning' them to the ravening hordes around them will solve the problem. Spinage is guilty of misrepresentation here (and in many places in his papers) where he presents the reader with such simplistic choices. One obvious alternative is not 'abandoning' such protected areas but transferring proprietorship of them to the local communities under contractual agreements with negotiated terms and conditions. In this same section, it is difficult to see what point Spinage is trying to make when he notes the need for further devolution of powers to smaller units in the CAMPFIRE programme. McIvor (1997) is not the source of this recommendation: it was made by me in draft legislation submitted to the Zimbabwe Ministry of Environment and Tourism in 1994.

His parting shot-that sociologists and anthropologists should not become involved in the management of protected areas because they are likely to see animals and plants only as useful in satisfying human demands-is less than gracious. Most 'conservationists' need some form of 'reality-check' and this is provided by social scientists. In developing the CAMPFIRE programme in 1984 (Martin, 1986), I turned to the Centre for Applied Social Sciences at the University of Zimbabwe for help and it has not only led to a long and fruitful collaboration but also convinced me that ecologists may be the least suitable people to decide on the conservation needs of the public at large.

There is a very real danger that any protracted debate over the issues Spinage has raised could lead to nonproductive bickering. It is perhaps as well to conclude this review by returning to Spinage's central tenet that if protected areas are failing it is because of increases in human populations and the availability of modern weapons and not because of the imposition of alien concepts on resident indigenous peoples. Although nowhere in this paper is proof positive established for this assertion, perhaps the choices with which Spinage presents us are irrelevant. The population explosion is a 
reality and perhaps the greatest chance of survival for protected areas lies not in any partial involvement of the peoples that surround them but in a genuine handover of control. Only when the costs and benefits of protected areas are properly internalized in a single set of accounts, is it likely that the 'Spaceship Earth' syndrome (in this case 'Spaceship Community') will result in the necessary homeostatic mechanisms coming into play to limit population growth.

\section{R. B. Martin}

Chairman, IUCN/SSC Southern Africa Sustainable Use

Specialist Group

PO Box MP4 Mount Pleasant

Harare, Zimbabwe

E-mail: sasusg@moost.icon.uz.zw

\section{References}

Bell, R.H.V. (1987) Conservation with a human face: conflict and reconciliation on African land use planning. In Conservation in Africa-People, Policies and Practice (eds D. Anderson and R. Grove), pp. 79-101. Cambridge University Press, Cambridge.

Child, G. (1995) Managing wildlife successfully in Zimbabwe. Oryx, 29, 171-177.

CBD (1998) Report of the Workshop on the Ecosystem Approach. Document UNEP/CBD/COP/4/Inf. 9 (March 1998).

Cumming, D.H.M., Fenton, M.B., Rautenbach, I.L. et al. (1997) Elephants, woodlands and biodiversity in southern Africa. South African Journal of Science, 93, 231-236.

Ghimire, K.B. \& Pimbert, M.P. (eds) (1997) Social Change and Conservation. Environmental Politics and Impacts of National Parks and Protected Areas. Earthscan, London.

Graham, A.D. (1973) The Gardeners of Eden. George Allen \& Unwin, London.

Martin, R.B. (1978) Project WINDFALL (Wildlife Industry's New Development for All [in the Sebungwe]). Project document submitted and approved by the Department of National Parks and Wild Life Management, Zimbabwe.

Martin, R.B. (1986) The Communal Areas Management Programme for Indigenous Resources (CAMPFIRE). Project proposal published by Department of National Parks and Wild Life Management, Zimbabwe.

Martin, R.B. (1993) Should Wildlife Pay its Way? Keith Roby Memorial Address, Murdoch University, Perth, Western Australia, 8 December 1993. Reprinted by Department of National Parks and Wild Life Management, Harare, Zimbabwe.

Martin, R.B. (1996) Integrated conservation and development: a redefined role for State bureaucracies. In Communities and Sustainable Use-Pan-African Perspectives (eds N. Christoffersen, B. Campbell and J. du Toit), pp. 34-44. Proceedings of the Pan African Symposium on Sustainable Use of Natural Resources and Community Participation, Harare, 24-27 June 1996. IUCN Regional Office for Southern Africa, Harare.

Mclvor, C. (1997) Management of wildlife, tourism and local communities in Zimbabwe. In Social Change and Conservation. Environmental Politics and Impacts of National
Parks and Protected Areas (eds K. B. Ghimire and M. P. Pimbert), pp. 214-238. Earthscan, London.

Murphree, M.W. (1997) Synergising Conservation Incentives. Social and Anthropological Dimensions of Sustainable Use. Presentation to the STAP Expert Workshop on the Sustainable Use of Biodiversity, Kuala Lumpur, Malaysia, 24-26 November 1997.

Nduku, W. \& Martin, R.B. (1991) Development of the Zimbabwe National Conservation Strategy for Black Rhino. In Rhinoceros Biology and Conservation. Proceedings of the International Rhino Conference, May 1991, San Diego, USA.

Parker, I. \& Amin, M. (1983). Ivory Crisis. Chatto \& Windus, London.

Peluso, N.L. (1992) Coercing conservation: the politics of state resource control. In The State and Social Power in Global Environment Politics (eds R. D. Lipschutz and K. Conca). Columbia University Press, New York.

SASUSG (1998) Sustainability of State Conservation Areas. Presentation by G.F.T. Child and B.A Child in Report of the Fourth Meeting of the SASUSG Steering Committee, Kruger National Park, January 1998. Southern Africa Sustainable Use Specialist Group, PO Box MP4, Mount Pleasant, Harare, Zimbabwe.

Spinage, C. (1996) The rule of law and African game-a review of some trends and concerns. Oryx, 30(3), 178-186.

Spinage, C. (1998) Social change and conservation misrepresentation in Africa. Oryx, 32(4), 265-276.

\section{Interpreting current levels of poaching of African elephants}

Ovejero (1998) stated that 'the constant dissemination of rumours, anecdotal information and unsubstantiated data (e.g. Orenstein, 1997; EIA, 1997, in litt.) on current levels of poaching might actually undermine the efforts of those operating on the ground to prevent poaching and even stimulate the illegal killing of elephants'. We refute the allegation that the EIA (Environmental Investigation Agency) is in any way involved with undermining efforts to protect elephants, let alone contributes to the killing of them. By citing EIA as a reference, Ovejero implies that we have been involved in spreading rumours that poaching is on the increase as a result of the CITES downlisting decision. This is entirely inaccurate.

The EIA remains concerned that the decisions relating to the African elephant taken at the CITES Conference in Harare in June 1997 may have adverse effects on the level of poaching of elephants, illegal trade in ivory and in generating unsustainable levels of consumer demand for ivory. However, at no time has EIA issued statements, reports or other communications stating that such negative effects can currently be shown to be taking place.

The EIA is actively engaged in the monitoring of elephant poaching and the ivory trade and will continue 
to be involved. With the experience, knowledge and expertise that the EIA has acquired over 12 years of intensive investigations and research into the illegal trade in ivory, it is well qualified to judge the possible consequences of the downlisting decision. However, at this stage, the EIA believes that it is impossible to discern trends in poaching levels or illegal trade in ivory arising from the CITES decision to downlist the elephant populations of Botswana, Namibia and Zimbabwe-quite simply it is too early to draw definitive conclusions or even compile conclusive data showing changes over time. At no stage has EIA stated that poaching or illegal trade in ivory has increased since the Harare CITES meeting.

The EIA respects the decision of the Parties to CITES to downlist the three elephant populations, despite our concerns about the potential impacts, and will continue to work within the CITES community to ensure the effective implementation and enforcement of the Convention.

Steve Trent, Campaigns Director

Environmental Investigation Agency Ltd

69-85 Old Street

London, EC1V 9HX, UK

E-mail: eiauk@gn.apc.org

\section{Reference}

Ovejero, J. (1997) Interpreting current levels of poaching of African elephants. Oryx, 32, 85-86.

The letter from EIA that Ovejero cited, dated 1 August 1997 and circulated widely, is reproduced in part below. The last sentence is the one to which Ovejero was referring to in his citation.

Editor

Environmental Investigation Agency Ltd 1 August 1997

As you will now be aware the elephant downlisting proposals submitted by Namibia, Botswana and Zimbabwe were adopted at the recent meeting of the Tenth Conference of the Parties to CITES in Harare, Zimbabwe. The Environmental Investigation Agency is very concerned that the limited legal trade that will be allowed in 21 months time will give cover to an increased illegal trade and an escalation in poaching will be the result. EIA is therefore assembling a database to monitor any poaching or movement of illegal ivory trade throughout the world. To ensure that we have complete up-to-date information and gain an accurate global picture we need to hear from you if there are any incidents of poaching, illegal trade in ivory or ivory seizures so that we can accurately record the information and build a complete picture of the situation. All sources of information will remain confidential if you so wish. Information could be from radio, television, print news coverage or even be anecdotal.

\section{Landmine clearance-its probable effect on Angolan biodiversity}

At least 85 million and possibly more than 100 million unexploded landmines currently lie scattered through at least 62 countries (Human Rights Watch, 1993). As well as their devastating medical, social and economic effects on the predominantly rural populations that depend on the infested lands for subsistence, landmines can also seriously damage wildlife populations of animals that inadvertently stumble upon them. In Angola, one of the most landmineinfested countries in the world, an estimated 6-10 million unexploded landmines remain. Although nobody doubts that the clearance of landmines is an imperative priority for any affected country, it is an unfortunate side-effect of landmine clearance that many hectares of land are slashed and cleared after decades of human absence to make way for agriculture and habitation. The expanding network of minefree roads provides access to areas previously inaccessible and devoid of human influence, and it is feared that such changes in land-use patterns will lead to widespread environmental degradation.

In Angola, landmines are concentrated in six to eight of the 18 Angolan provinces and are believed to affect over 50 per cent of the country, in a band running from the north-west border with the Congo to the south-east border with Namibia. Unfortunately, not all mine fields have been mapped and recorded by the troops who laid them, thus making it almost impossible to determine with exactitude the scale of the problem at a national level. This general lack of reliable information on the location of landmines has led to an extensive mine survey programme being conducted jointly by all major mine-clearing organizations. Initial surveys to identify mined or suspected mined areas have already been completed for nine provinces, covering about 80 percent of the population. Substantial coverage has been achieved for five other provinces, and all surveys were planned to be completed by the end of 1998 (Anon., 1998).

Humanitarian campaigns have been established with significant international support to assist in the clearance of such weapons of mass destruction. Seven 
the common priorities of all NGOs working on theclearance of landmines in Angola is to ensure the safe return of the estimated 1-12 million internally displaced people, or IDPs, to their homes. At least 300,000 people are also thought to be refugees in neighbouring countries (UCAH, 1997), and it is this expected homeward movement that could potentially lead to a vast change in land-use patterns. In recent years the return of IDPs and refugees was limited by insecure conditions. Even more recently, continued insecurity has not only prevented the return of about 85 per cent of the registered IDPs, but has resulted in new displacements, especially because residual rebel troop attacks have increased in frequency since April and May 1998.

Mine clearing work continues despite this volatile situation. To date, 1766 mine fields have been identified and $1436 \mathrm{sq} \mathrm{km}$ of high-priority land has been cleared of mines by NGOs. Much of this has been accomplished by the German-based People Against Landmines ( $\mathrm{MgM}$ ) through innovative animal-aided, mechanically assisted, manual clearance of $195 \mathrm{~km}$ of road, which has opened c. $1224 \mathrm{sq} \mathrm{km}$ to resettlement. Other NGOs, which rely on predominantly manual methods of mine detection, concentrate efforts on demining villages and fields where the topsoil would otherwise be destroyed. A further $32,732 \mathrm{sq} \mathrm{km}$ has been cleared nation-wide by Mechem Consultants, the UN's contract mine clearance organization, rehabilitating $4676 \mathrm{~km}$ of paved road in the process (Oelschig, 1997). However, travel by vehicle remains extremely dangerous anywhere on the national road network because of bandit attacks and, consequently, humanitarian efforts to repatriate refugees and resettle IDPs have failed.

Before the magnitude of the possible effects of landmine clearance on land use can be assessed, the total extent of land surface made accessible by cleared roads needs to be quantified. The impact should be greatest in areas where mined roads have been the only hindrance to land development. In those regions, for example the northern Bengo province where MgM is currently based, the effects of landmine removal are clearly visible within days of access being restored: smouldering hillsides, tree felling and timber export proposals being witnessed first hand. In other partsof the country, c. $150 \mathrm{~km}$ south-east of the capital Luanda, recently burned landscapes stretch from horizon to horizon, with no apparent sign of active resettlement. This poses the question of whether landmine clearance itself or the return of numerous people to their lands has the greater detrimental effect on bio- diversity. It seems as though the former may act as a catalyst for what may become an irreversible and perhaps unconsummated reaction. Cleared agricultural fields, on the other hand, suffer not only from the effects of years of abandon, but are also left littered with non-biodegradable and toxic garbage such as plastics and TNT. These are indubitably going to exert some influences on the chemical and physical structure of the soil, and this has led to doubts about the extent and time scale of operations culminating in the handing over of safe land to the local population.

Landmine clearance is likely to continue for many years to come. Thus, the threat of human activity to Angolan biodiversity is imminent. Population growth, excessive harvesting, habitat fragmentation, uncontrolled waste disposal and pollution all add to the problem. The pressures do not come only from rural populations. Increased migration to urban areas during hardship promotes the destruction of existing vegetation through expansion and land conversion. In addition, urban demands for biomass require fuelwood, industrial wood and other products such as fruit and wild animals from the surrounding areas. Nowhere are the effects of this more prominent than around the semi-permanent refugee camps outside Luanda, where the inhabitants have stripped the landscape of every twig for as far as the eye can see.

Conservation efforts in Angola remain largely utopic. Until recently, access to this war-torn nation has been largely impossible. Even now that some progress has been made to facilitate access, mostly to enable safer humanitarian intervention, expeditions by scientists are still not recommended. Unfortunately for science, however, now is the time to record the biodiversity assemblage of wild fauna and flora that may shortly be irreparably damaged or altogether removed from a unique, yet lamentably unnatural, reserve. It is only with increased awareness of these issues and, ultimately, political stability that landmine clearance and the restoration of accessibility can result in the intended human resettlement rather than the current incidental environmental degradation.

Christopher R. S. Barrio Froján

Department of Entomology

The Natural History Museum, Cromwell Road

London SW7 SBD, UK

Alfried P. Volger (corresponding author)

Department of Biology

Imperial College of Science, Technology and Medicine

Silwood Park, Ascot, Berkshire SL5 TTA, UK

E-mail:a.volger@nhm.ac.uk 


\section{References}

Anon. (1998) Country Profile: Angola. In Hidden Killers: The Global Landmine Crisis. Chapter 3. US Department of State, Bureau of Political-Military Affairs, Office of Humanitarian Demining programs, Washington DC.

Human Rights Watch (1993) Landmines - A Deadly Legacy. The Arms Project of Human Rights Watch and Physicians for Human Rights, USA.
Oelschig, F. (1997) Statement of Roads Cleared by Mechem Consultants (Humanitarian De-mining Specialists), Rua Commandante Dac Doi 19a, Bairro Azul, Luanda, Angola.

UCAH (United Nations Humanitarian Assistance Co-ordination Unit) (1997) Notes on the Humanitarian Situation, Luanda, Angola. 